\title{
Study on the Impact Factors of Campus Safety of College Students
}

\author{
Xiuping Sui \\ Shandong Jiaotong University, Shandong, China \\ WHSUI@163.com
}

\author{
Keywords: AHP, University Campus Safety; Impact Factors
}

\begin{abstract}
Campus safety management is a prerequisite for the normal development of all University work. Without a safe educational environment, the development of colleges and universities will not be guaranteed. In this regard, colleges and universities should attach great importance to the safety management of the campus, and all safety guarantees must be put in place. This article starts from the current situation of campus safety management around the current high domestic level. The influence factors in campus safety management are studied, and some feasible countermeasures are put forward to improve campus safety management.
\end{abstract}

\section{Introduction}

Colleges and universities are important positions for training high-quality construction talents for the society. All are prerequisites for the conduct of various educational research studies. Therefore, colleges and universities should attach great importance to Campus safety management can ensure the normal development of colleges and universities. At present, the management of colleges and universities in China The rational form usually uses a more open model, which facilitates students 'contact with the outside world. However, this kind of management mode also has a negative impact on the security management of the campus. The criminals provided convenience; The development of colleges and universities has led to the development of the economy around the campus. At the same time, it has brought some problems to the school order. In the face of existing security risks, perfect high The safety management measures of the school have become the top priority of the current management work. Campus safety management is a prerequisite for the normal development of all University work. Without a safe educational environment, the development of colleges and universities will not be guaranteed. In this regard, colleges and universities should attach great importance to the safety management of the campus, and all safety guarantees must be put in place. This article starts from the current situation of campus safety management around the current high domestic level. The influence factors in campus safety management are studied, and some feasible countermeasures are put forward to improve campus safety management.

\section{Analytic Hierarchy Process (AHP)}

Ahp is a systematic and hierarchical multi-objective Decision analysis method, which can be measured data, expert rating and scoring The analyst's objective judgment is effectively combined. Analytic hierarchy. This idea is: first, according to the analysis of the nature of the problem and to achieve. The goal is to decompose the elements into hierarchical hierarchies according to their attributes and membership relations.

\section{System of the Influence Factors of Impact Factors of Campus Safety of College Students}

We have the first class indicators and the second class indicators as following:

Study on the Impact Factors of Campus Safety of College Students

campus facilities: laboratory, laboratory equipment, campus facility, Sports ground

safety management: emergency plan, safety regulations, safety law, safety education

safety culture, mental health, safety propaganda, thought and conduct. 
Off-campus factors: bad information, family factors, parent education, majeure force

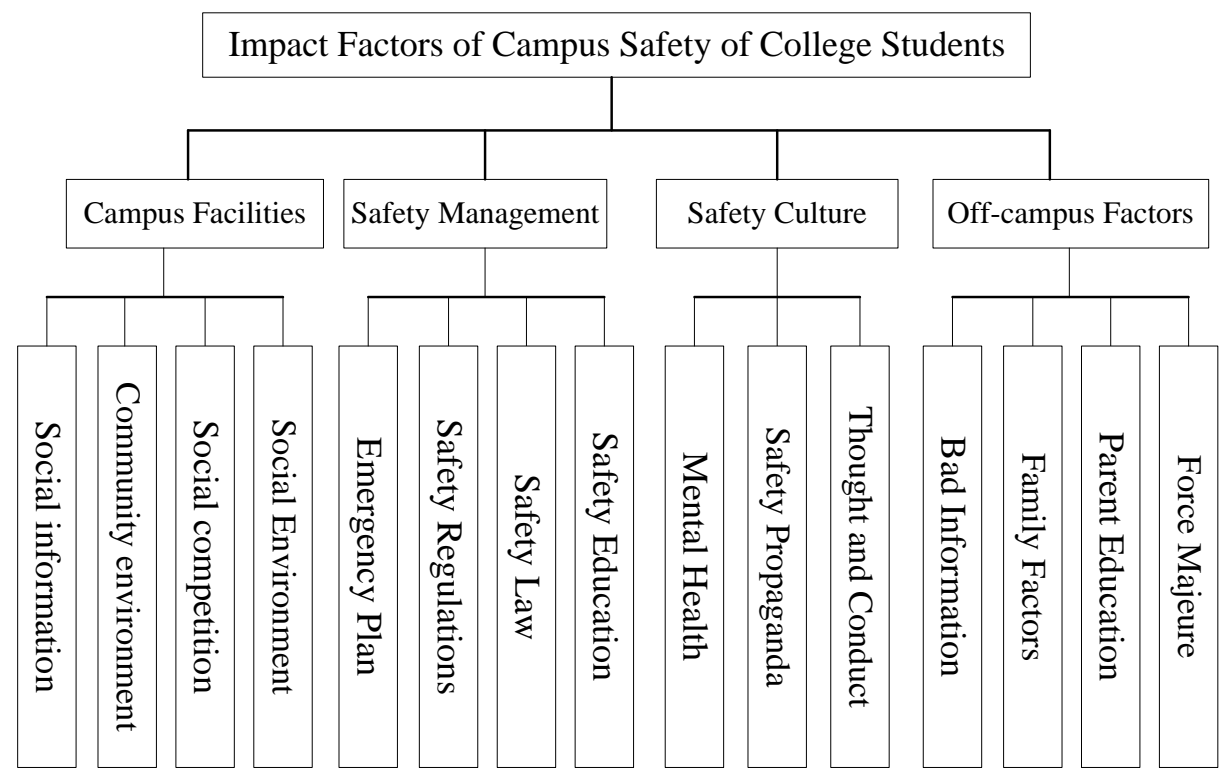

Figure 1. Campus Safety of College Students Model

\section{Setup Judgment Matrices}

The hierarchical structure of this paper is based on the evaluation index system of Influence Factors of Impact Factors of Campus Safety of College Students and test the consistency, and weigh the value of each index layer as follow:

$\mathrm{A} 0$

$\left[\begin{array}{cccc}1 & 2 & 3 & 5 \\ 1 / 2 & 1 & 3 & 4 \\ 1 / 3 & 1 / 3 & 1 & 3 \\ 1 / 5 & 1 / 4 & 1 / 3 & 1\end{array}\right]$

$W=(0.4609,0.3104,0.1560,0.0726)$

$\lambda_{\max }=4.1087, C I=0.0362, C R=0.0403<0.1$

\section{Al}

$\left[\begin{array}{cccc}1 & 1 / 3 & 4 & 2 \\ 3 & 1 & 5 & 3 \\ 1 / 4 & 1 / 5 & 1 & 1 / 2 \\ 1 / 2 & 1 / 3 & 2 & 1\end{array}\right]$

$W=(0.2575,0.5114,0.0800,0.1511)$

$\lambda_{\max }=4.0810, C I=0.0270, C R=0.0300<0.1$ 


$$
\begin{aligned}
& {\left[\begin{array}{cccc}
1 & 1 / 5 & 1 / 3 & 1 / 2 \\
5 & 1 & 3 & 5 \\
3 & 1 / 3 & 1 & 2 \\
2 & 1 / 5 & 1 / 2 & 1
\end{array}\right]} \\
& W=(0.0835, \quad 0.5601, \quad 0.2268, \quad 0.1296) \\
& \lambda_{\max }=4.0597, C I=0.0199, C R=0.0221<0.1
\end{aligned}
$$

\section{A3}

$$
\left[\begin{array}{ccc}
1 & 1 / 3 & 3 \\
3 & 1 & 7 \\
1 / 3 & 1 / 7 & 1
\end{array}\right]
$$

$W=(0.2430,0.6688,0.0882)$

$\lambda_{\text {max }}=3.007, C I=0.0035, \quad C R=0.0060<0.1$

$$
\begin{aligned}
& A 4 \\
& {\left[\begin{array}{cccc}
1 & 1 / 5 & 1 / 3 & 2 \\
5 & 1 & 3 & 6 \\
3 & 1 / 3 & 1 & 3 \\
1 / 2 & 1 / 6 & 1 / 3 & 1
\end{array}\right]} \\
& W=(0.1153,0.5644,0.2440,0.0764) \\
& \lambda_{\max }=4.0796, \quad C I=0.0265, C R=0.0295<0.1
\end{aligned}
$$

In the second class indicators, campus facilities includes laboratory, laboratory equipment, campus facility, Sports ground, and the laboratory is important. In safety management includes emergency plan, safety regulations, safety law, safety education and emergency plan is more important. In safety culture, mental health, is more important.In ff-campus factors, bad informationis more important.

\section{Conclusion}

Efforts should be made to build and build a healthy and harmonious new campus benefits Benefit relationship, pay attention to campus safety management for teaching, scientific research, management The advocacy of management service and safety management team for the service awareness of teachers and students, Make efforts to build a safe campus with the interests of teachers and students integrated school development The goal of the exhibition is the same as the vision of the development of teachers and students Body. Learn to choose safety over convenience in case of conflict.Strengthen democratic management, involving the rights and interests of teachers and students of the security management regulations. The system must enter the research and decision-making process in the process and process. With "well-intentioned security management" to strive for maximum consensus and recognition, push dynamic campus security management from "forming discourse circle" to "improving discourse power".

\section{References}

[1] Dingyuemin. Research on the Evaluation Method of Personnel Quality Based on Medical Personnel Competence Model. Human Resources Management, 2015(2), pp.195-196. 
[2] Arthur S. Levine, Margaret C. McDonald, Charles E. Bogosta. Sino-U.S. partnerships in research, education, and patient care: The experience of the University of Pittsburgh and UPMC. Science China Life Sciences, 2017, 60 (10), pp.1150-1156.

[3] Frederic P, Philipp K, Roger S. Experience Co-creation in Financial Services:An Empirical Exploration. Journal of Service Management, 2015, 26 (2), pp.295-320.

[4] Yu Huixian. Recruitment Based on Competency Model[J].Chinese and Foreign Exchanges, 2017,(17): 30

[5] Assante M, Candela L, Castelli D. Are Scientific Data Repositories Coping with Research Data Publishing. Data Science Journal, 2016(15), pp.1-24.

[6] Dnyandeo Dattatraya Shinde, Ramjee Prasad. Application of AHP for Ranking of Total Productive Maintenance Pillars. Wireless Personal Communications, 2018, 100 (2), pp.449-462.

[7] Saeid Maknouni, Mohammad Zare, Ezzatollah Raeisi. Determining the hard rock groundwater pathway in Golgohar complex formation using hydrochemical data in AHP. Arabian Journal of Geosciences, 2018, 11 (8), pp.1-16. 